\title{
A Case of Rapidly Progressive Primary Sclerosing Cholangitis Requiring Liver Transplantation
}

\author{
Tae Seop Lim, M.D. ${ }^{1}$, Jun Yong Park, M.D. ${ }^{1}$, Soon II Kim, M.D. ${ }^{2}$ \\ Huapyong Kang, M.D. ${ }^{1}$ and Moon Jae Chung, M.D. ${ }^{1}$
}

Department of Internal Medicine, Yonsei Institute of Gastroenterology', Department of Surgery, Research Institute for Transplantation², Yonsei University College of Medicine, Seoul, Korea

\begin{abstract}
Primary sclerosing cholangitis (PSC) is a slowly progressive cholestatic liver disease. In cases of PSC, liver transplantation is the only effective treatment that can delay the disease's natural course. We report a case of rapidly progressive PSC requiring liver transplantation. A 52-year-old woman visited our hospital with abdominal pain. There was no evidence of PSC, as there was no elevation in cholestatic liver enzymes at her first visit. Although her total bilirubin was in a normal range at the initial visit, liver dysfunction progressed rapidly. Despite endoscopic procedures and ursodeoxycholic acid intake, total bilirubin levels rose to $18.9 \mathrm{mg} / \mathrm{dL}$, and liver transplantation was performed 17 months after her first visit. PSC was pathologically confirmed after liver transplantation.
\end{abstract}

Key Words: Primary sclerosing cholangitis, Liver transplantation, Ursodeoxycholic acid, Endoscopic retrograde cholangiopancreatography, Magnetic resonance cholangiopancreatography

중심 단어: 원발성 경화성 담관염, 간이식, 우루소데옥시콜산, 내시경적 역행성 담췌관조영술, 자기공명담췌관조영술

\section{Introduction}

Primary sclerosing cholangitis (PSC) is a chronic cholestatic bile duct disease. According to a recent meta-analysis, its incidence was 0.77 per 100,000 person-years(1). It is a rare disease and seems to occur at lower frequencies in Asia and Southern Europe than in America and Northern Europe(2).

PSC is often fatal as there are no effective treatments which can halt its progression with the exception of liver transplant. In the case described here, there was no evidence of PSC except the elevated cholestatic liver enzymes at the initial visit of our hospital. However, 17 months later, the patient's liver dysfucntion had rapidly progressed, and a liver transplantation was performed.

Correspondence: Moon Jae Chung, Department of Internal Medicine, Yonsei Institute of Gastroenterology, Yonsei University College of Medicine, 50 Yonsei-ro, Seodaemun-gu, Seoul 120-752, Korea Tel: +82-2-2228-1930, Fax: +82-2-393-6884 E-mail: mjchung@yuhs.ac

Received : November 30, 2012, Revised : February 14, 2013, Accepted : March 6, 2013

\section{Case Report}

In September 2010, a 52-year-old woman visited our hospital presenting with abdominal pain which had been present for 1 month. She was taking antihypertensive medication. Her sclera was not icteric, and there was no abdominal tenderness. A liver function test revealed the following: aspartate aminotransferase (AST) 110 IU/L, alanine aminotransferase (ALT) 119 IU/L, total bilirubin $0.3 \mathrm{mg} / \mathrm{dL}$, alkaline phosphatase (ALP) $400 \mathrm{IU} / \mathrm{L}$, and $\gamma$-glutamyl transpeptidase $(\gamma$-GT $)$ 592 IU/L. Her hepatitis B surface antigen, antibody to hepatitis $\mathrm{C}$ virus, antihepatitis A virus immunoglobulin $\mathrm{M}$ were all negative. Tumor markers were carcinoembryonic antigen $1.18 \mathrm{ng} / \mathrm{mL}$ and CA $19-924.3 \mathrm{U} / \mathrm{mL}$. Esophagogastroduodenoscopy, colonoscopy, and abdomen computed tomography showed no abnormal findings. Cholestatic liver diseases such as PSC, primary biliary cirrhosis, or nonalcoholic fatty liver disease were suspected due to the elevated cholestatic liver enzyme levels. For further evaluation, autoimmune markers were checked. Her autoimmune markers: perinuclear antineutrophil cytoplasmic antibody, cytoplas- 
mic antineutrophil cytoplasmic antibody, antinuclear antibody, antimitochondrial antibody, and antismooth muscle antibody were all negative. Immunoglobulin $G$, A, M quantification were 1,460, 192, and $261 \mathrm{mg} / \mathrm{dL}$, respectively, subclass immunoglobulin G4 level was $139.0 \mathrm{mg} / \mathrm{dL}$. Although the diagnosis was unclear, ursodeoxycholic acid (UDCA) intake was started at 10 $\mathrm{mg} / \mathrm{kg} / \mathrm{day}$, and serum ALP and aminotransferase levels decreased. However, after 8 months (May 2011), the patient's liver enzyme levels rose to: AST $65 \mathrm{IU} / \mathrm{L}$, ALT $174 \mathrm{IU} / \mathrm{L}$, total bilirubin $1.4 \mathrm{mg} / \mathrm{dL}$, ALP $518 \mathrm{IU} / \mathrm{L}$, and $\gamma$-GT $686 \mathrm{IU} / \mathrm{L}$. We performed a liver biopsy and the pathology showed a mild degree of lobular and portal activity, and portal fibrosis suggestive of chronic hepatitis (Fig. 1A). The dose of UDCA was increased to $15 \mathrm{mg} / \mathrm{kg} /$ day. After 12 months (September 2011), the patient's total bilirubin rose to $4.0 \mathrm{mg} / \mathrm{dL}$. In order to evaluate the cause of the obstructive jaundice, magnetic resonance cholangiopancreatography (MRCP) (Fig. 2A), and endoscopic retrograde cholangiopancreatography (ERCP) (Fig. 2B) were performed. These findings revealed multiple stones, strictures, and dilata- tions of intrahepatic ducts, suggestive of PSC. Endoscopic shpincterotomy was done and an endoscopic nasobiliary drainage tube was inserted by ERCP. After 15 months (December 2011), the patient's total bilirubin and direct bilirubin rose to 13.9 and $11.1 \mathrm{mg} / \mathrm{dL}$, respectively, and so MRCP was performed again. The mucosal irregularity had not changed from what was seen in the previous MRCP. To relieve the jaundice, stones were removed from the common bile duct and intrahepatic ducts by ERCP and percutaneous transhepatic choledochoscopy (PTCS), respectively. A biopsy was performed using PTCS on an intraductal mucosal lesion showing nodularity in the hilum, and the result showed fibrous exudates with chronic inflammatory cell infiltration. Despite extracting the stones, total bilirubin rose again to $18.9 \mathrm{mg} / \mathrm{dL}$ (Fig. 3), and direct bilirubin rose to $15.4 \mathrm{mg} / \mathrm{dL}$. Although there were no complications such as ascites, hepatic encephalopathy, bleeding, and hepatorenal syndrome, there was no treatment of choice to halt progression of liver dysfunction except liver transplantation. The patient's MELD score was 26, and Child-Pugh score was 9. A

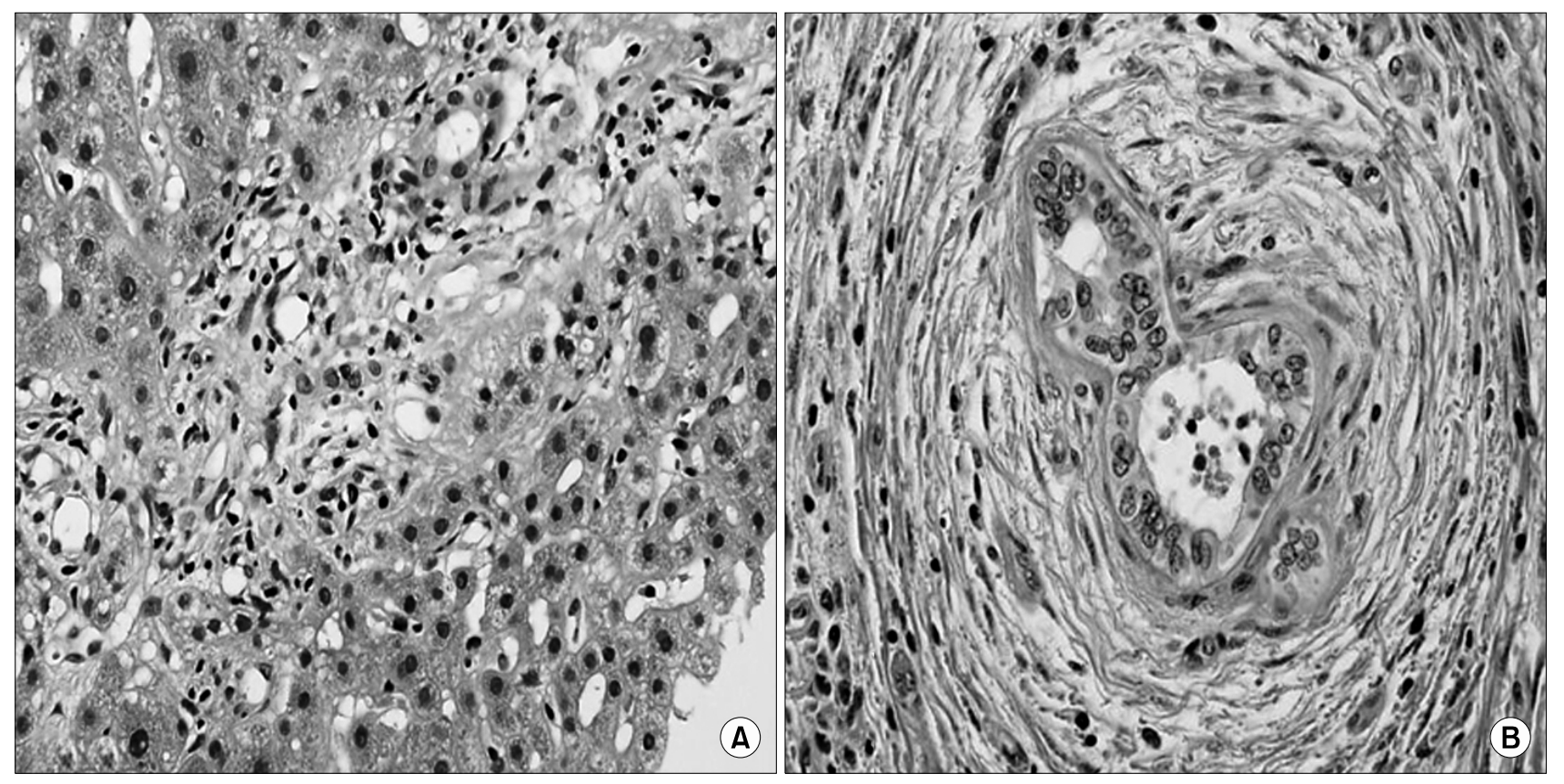

Fig. 1. (A) Eight months after the initial diagnosis of primary sclerosing cholangitis (PSC), the patient's liver biopsy showed a mild degree of lobular and portal activity, and portal fibrosis suggestive of chronic hepatitis (HE stain, $\times 400$ ). (B) After liver transplantation, which was done 17 months after the initial diagnosis, surgical pathology showed periductal lamellar fibrosis, called "onion-skin," a typical finding of PSC (HE stain, $\times 400)$. 



Fig. 2. Twelve months after the initial diagnosis of primary sclerosing cholangitis (PSC), (A) magnetic resonance cholangiopancreatography and (B) endoscopic retrograde cholangiopancreatography findings showed multiple dilatations and strictures of intrahepatic ducts, suggestive of PSC.

Fig. 3. The trend of total bilirubin, alkalaine phosphatase, and alanine aminotransferase (ALT) was described. Abbreviations: PTCS, percutaneous transhepatic choledochoscopy; ERCP, endoscopic retrograde cholangiopancreatography; LT, liver transplantation; ALP, alkaline phosphatase; $T B$, total bilirubin.

liver transplant from living donor with duct to duct anastomosis was performed at 17 months (February 2012) after the initial visit of our hospital. The explanted liver weighed $1,600 \mathrm{~g}$ and measured 24 (right to 1 eft $) \times 15$ (superior to inferior $\times 12 \mathrm{~cm}$ (anterior to posterior) (Fig. 4). The surgical pathology of explanted liver reported a segmental bile duct showing concentric fibrosis suggestive of PSC (Fig. 1B). The patient's human leukocyte antigen (HLA) serotyping was A1, A24, B51, B52, DR1, and DR15. The elevated bilirubin levels rapidly decreased, and were in the normal range by 21 days after surgery. The patient is on tacrolimus hydrate since liver transplantation. General condition of the patients was markedly improved without recurrence of cholangitis. However, at 5 months after liver transplantation, the anastomosis site stricture

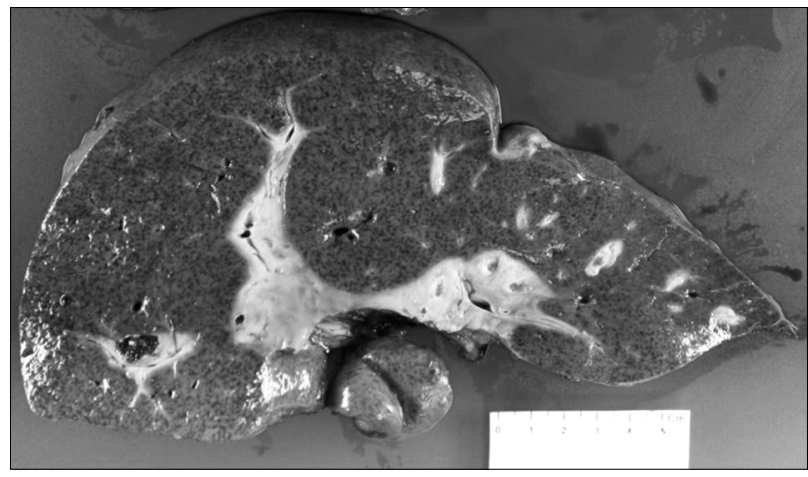

Fig. 4. Gross finding of the explanted liver. The liver was macronodular, and diffusely bile stained.

was found in abdomen computed tomography, and percutaneous biliary tract drainage (PTBD) was inserted. At 11 months after liver transplantation, PTBD was re- 
moved, and endoscopic retrograde biliary drainage was inserted.

\section{Discussion}

PSC is a chronic cholestatic liver disease leading to liver cirrhosis and liver failure. It is a slowly progressive disease(3) and the median survival from diagnosis to liver transplantation or death is $9.6 \sim 12$ years $(4,5)$. Previous studies have reported that HLA-DR4 and DRw52a are markers for rapid disease progression in $\operatorname{PSC}(6,7)$, but this is still controversial(8). In our patient, HLD-DR4 and DRw52a were not observed, but her liver dysfunction progressed rapidly, and 17 months after her initial diagnosis a liver transplant was necessary.

PSC can be diagnosed when cholangiography shows multifocal strictures and segmental dilatations of bile ducts with elevated cholestatic liver enzyme levels(9). Inflammatory bowel disease is found in 60 80\% of PSC patients and can be a clue for PSC diagnosis(9). In this case, the patient first visited our hospital complaining of abdominal pain without any evidence of inflammatory bowel disease, and laboratory results revealed elevated levels of alkalaine phosphatase and aminotransferase without any elevation of total bilirubin.

Although liver biopsies can be done to determine the stage of PSC and to exclude coexisting liver diseases, this is not essential for diagnosis. In $98.7 \%$ of PSC patients, liver biopsies showed no atypical findings(10). In this case, a liver biopsy was done but only indicated chronic hepatitis. The nodular lesion at the hilum portion of an intrahepatic duct was also biopsied by PTCS to exclude cholangiocarcinoma, which is often concomitant with PSC, and the pathology showed chronic inflammation without malignancy. Nine months after the first liver biopsy, a surgical specimen obtained during the liver transplantation showed periductal lamellar fibrosis, a typical pathologic finding in PSC.

Until now, there has been no definitive treatment for PSC except liver transplantation. Some retrospective studies reported survival benefits in PSC when endoscopic treatments such as sphincterotomy, balloon di- latation, stent insertion, or stone extraction were performed to relieve dominant strictures $(11,12)$. A dominant stricture is a stenosis with a diameter of $\leq 1.0$ $\mathrm{mm}$ in a hepatic duct or $\leq 1.5 \mathrm{~mm}$ in a common duct(13). However, in PSC, the effectiveness of these endoscopic procedures is still unclear because there have been no randomized controlled studies to report on the benefits(9). Some studies have reported that UDCA improved liver function, but they failed to demonstrate if it halted PSC progression(14-16). Furthermore, recent studies revealed that high-dose UDCA $(28 \sim 30$ $\mathrm{mg} / \mathrm{kg} /$ day) did not improve patient survival and was associated with severe adverse effects $(17,18)$. Due to this lack of clarity of the effectiveness of UDCA, recent guidelines recommend against the use of UDCA(9).

In summary, we described a patient with rapidly progressive PSC, which was pathologically confirmed after liver transplantation. PSC is a very rare disease in Korea and is typically a chronic disease. The patient visited our hospital because of abdominal pain without jaundice, but after 17 months, liver transplantation was performed due to decreased liver function. Although an endoscopic treatment was performed and standard-dose UDCA was administered, disease progression was not slowed. After liver transplantation, the patient's liver function recovered fully.

\section{REFERENCES}

1) Molodecky NA, Kareemi H, Parab R, Barkema HW, Quan H, Myers RP, et al. Incidence of primary sclerosing cholangitis: a systematic review and meta-analysis. Hepatology 2011;53:1590-9.

2) Milkiewicz P, Wunsch E. Primary sclerosing cholangitis. Recent Results Cancer Res 2011;185:117-33.

3) Rosen CB, Nagorney DM, Wiesner RH, Coffey RJ Jr, LaRusso NF. Cholangiocarcinoma complicating primary sclerosing cholangitis. Ann Surg 1991;213:21-5.

4) Broomé U, Olsson R, Lööf L, Bodemar G, Hultcrantz R, Danielsson A, et al. Natural history and prognostic factors in 305 Swedish patients with primary sclerosing cholangitis. Gut 1996;38:610-5.

5) Tischendorf JJ, Hecker H, Krüger M, Manns MP, Meier PN. Characterization, outcome, and prognosis in 273 patients with primary sclerosing cholangitis: a single center study. Am J Gastroenterol 2007;102:107-14.

6) Mehal WZ, Lo YM, Wordsworth BP, Neuberger JM, Hubscher SC, Fleming KA, et al. HLA DR4 is a marker 
for rapid disease progression in primary sclerosing cholangitis. Gastroenterology 1994;106:160-7.

7) Farrant JM, Doherty DG, Donaldson PT, Vaughan RW, Hayllar KM, Welsh KI, et al. Amino acid substitutions at position 38 of the DR beta polypeptide confer susceptibility to and protection from primary sclerosing cholangitis. Hepatology 1992;16:390-5.

8) Olerup O, Olsson R, Hultcrantz R, Broome U. HLADR and HLA-DQ are not markers for rapid disease progression in primary sclerosing cholangitis. Gastroenterology 1995;108:870-8.

9) Chapman R, Fevery J, Kalloo A, Nagorney DM, Boberg KM, Shneider B, et al. Diagnosis and management of primary sclerosing cholangitis. Hepatology 2010;51:66078.

10) Burak KW, Angulo P, Lindor KD. Is there a role for liver biopsy in primary sclerosing cholangitis? Am J Gastroenterol 2003;98:1155-8.

11) Baluyut AR, Sherman S, Lehman GA, Hoen H, Chalasani N. Impact of endoscopic therapy on the survival of patients with primary sclerosing cholangitis. Gastrointest Endosc 2001;53:308-12.

12) Gluck M, Cantone NR, Brandabur JJ, Patterson DJ, Bredfeldt JE, Kozarek RA. A twenty-year experience with endoscopic therapy for symptomatic primary sclerosing cholangitis. J Clin Gastroenterol 2008;42:1032-9.
13) Stiehl A, Rudolph G, Klöters-Plachky P, Sauer P, Walker S. Development of dominant bile duct stenoses in patients with primary sclerosing cholangitis treated with ursodeoxycholic acid: outcome after endoscopic treatment. J Hepatol 2002;36:151-6.

14) Shi J, Li Z, Zeng X, Lin Y, Xie WF. Ursodeoxycholic acid in primary sclerosing cholangitis: meta-analysis of randomized controlled trials. Hepatol Res 2009;39:86573.

15) Poropat G, Giljaca V, Stimac D, Gluud C. Bile acids for primary sclerosing cholangitis. Cochrane Database Syst Rev 2011;(1):CD003626.

16) Triantos CK, Koukias NM, Nikolopoulou VN, Burroughs AK. Meta-analysis: ursodeoxycholic acid for primary sclerosing cholangitis. Aliment Pharmacol Ther 2011;34:90110 .

17) Lindor KD, Kowdley KV, Luketic VA, Harrison ME, McCashland T, Befeler AS, et al. High-dose ursodeoxycholic acid for the treatment of primary sclerosing cholangitis. Hepatology 2009;50:808-14.

18) Imam MH, Sinakos E, Gossard AA, Kowdley KV, Luketic VA, Edwyn Harrison M, et al. High-dose ursodeoxycholic acid increases risk of adverse outcomes in patients with early stage primary sclerosing cholangitis. Aliment Pharmacol Ther 2011;34:1185-92. 